\title{
A New Method to Evaluate the Reliability of the Relay Protection System in Intelligent Substation
}

\author{
Yaoliang Yan ${ }^{1}$, Lingjiang $\mathrm{Xu}^{2}$, Leiming Ding ${ }^{1}$, Weijie Qian ${ }^{1}$ and Shaoxuan Zhu ${ }^{3, *}$ \\ ${ }^{1}$ State Grid JiaXing Power Supply Company, JiaXing, China \\ ${ }^{2}$ State Grid ZheJiang Power Supply Company, ZheJiang, China \\ ${ }^{3}$ North China Electric Power University, BeiJing, China \\ ${ }^{*}$ Corresponding author
}

\begin{abstract}
At present, some studies have been done to evaluate the reliability of the relay protection system in intelligent substation, but all of them ignored a fact that the intelligent substation can effectively utilize redundant information to identify fault components and enhance the reliability of protection, which leads to underestimation of the system reliability. In view of the above problem, this paper presents a new method. Firstly, the architecture of protection system and the reliability of component in intelligent substation is analyzed. Then the effect of information redundancy and data exchange on the reliability of different types of protection is considered in the form of virtual branch. Finally, an example is given to verify the effectiveness of the proposed method.
\end{abstract}

Keywords-reliability evaluation; intelligent substation; protection system; virtual branch

\section{INTRODUCTION}

With the rapid development of IEC 61850 standard, high speed ethernet switching technology and intelligent equipment, intelligent substation has become the goal and trend of the development of substation integrated automation technology. Compared with the traditional substation, the relay protection system of intelligent substation based on IEC 61850 has great difference in both structure and components. As is known that the reliable operation of the relay protection system plays an important role in ensuring the safety of the equipment and the reliability of the power supply, so research on the reliability assessment of relay protection system in intelligent substation is of great significance.

Currently, methods widely used in the reliability assessment of relay protection system include reliability block diagrams(RBD) method ${ }^{[3-7]}$, fault tree analysis(FTA) method ${ }^{[8-}$ 9] and the Markov method ${ }^{[10-11]}$, among which the RBD method is widely applied because of its clear structure and simple calculation. Reference ${ }^{[3-6]}$ enumerates all the typical structures of protection system in intelligent substation and draws the reliability block diagram respectively, so as to calculate the reliability under different system structures. Reference ${ }^{[7]}$ adds the influence of primary system to the reliability evaluation of the station protection system, and proposed a equivalent reliability index with comprehensive consideration of the protection system and primary system. Reference [12] comprehensively considers the manufacturing cost of the protection system and the economic loss caused by the system failure, then establishes the reliability evaluation model considering the economy. However, the above reliability evaluation methods all ignore a fact that the intelligent substation can effectively utilize redundant information to identify fault components and enhance the reliability of protection, which leads to a underestimation of the system reliability.

In view of the above problems, this paper presents a reliability evaluation method of the relay protection system in smart substation considering virtual branch, which embodies the characteristics of the intelligent substation using redundant information to identify the fault components, so that the reliability of the protection system in the station is more reasonable.

\section{ARCHITECTURE OF RELAY PROTECTION SYSTEM IN INTELLIGENT SUBSTATION}

The intelligent substation can be logically divided into three equipment layers (process layer, interval layer and station layer), two network layers (process layer bus, station control layer bus), the equipment in each layer use high-speed ethernet to transmit data, and use MMS, GOOSE, SV message to realize digital information exchange ${ }^{[13]}$.

A typical architecture of protection system in $110 \mathrm{kV}$ intelligent substation is shown in Figure I. On one hand, the electrical quantity information collected by the electronic transformer is directly sent to the intelligent protection equipment after the processing of the merging unit ("direct collection"), on the other hand, it is sent to the SV network by the interval switch ("net collection"). Accordingly, the intelligent protection equipment can receive the information from the interval merging unit directly or from the SV network. After the analysis and processing of information, the intelligent protection equipment transmits the trip command to the intelligent terminal through the GOOSE network ("net tripping”) or directly through the optical fiber (“direct tripping”) to control the circuit breaker tripping or not. 


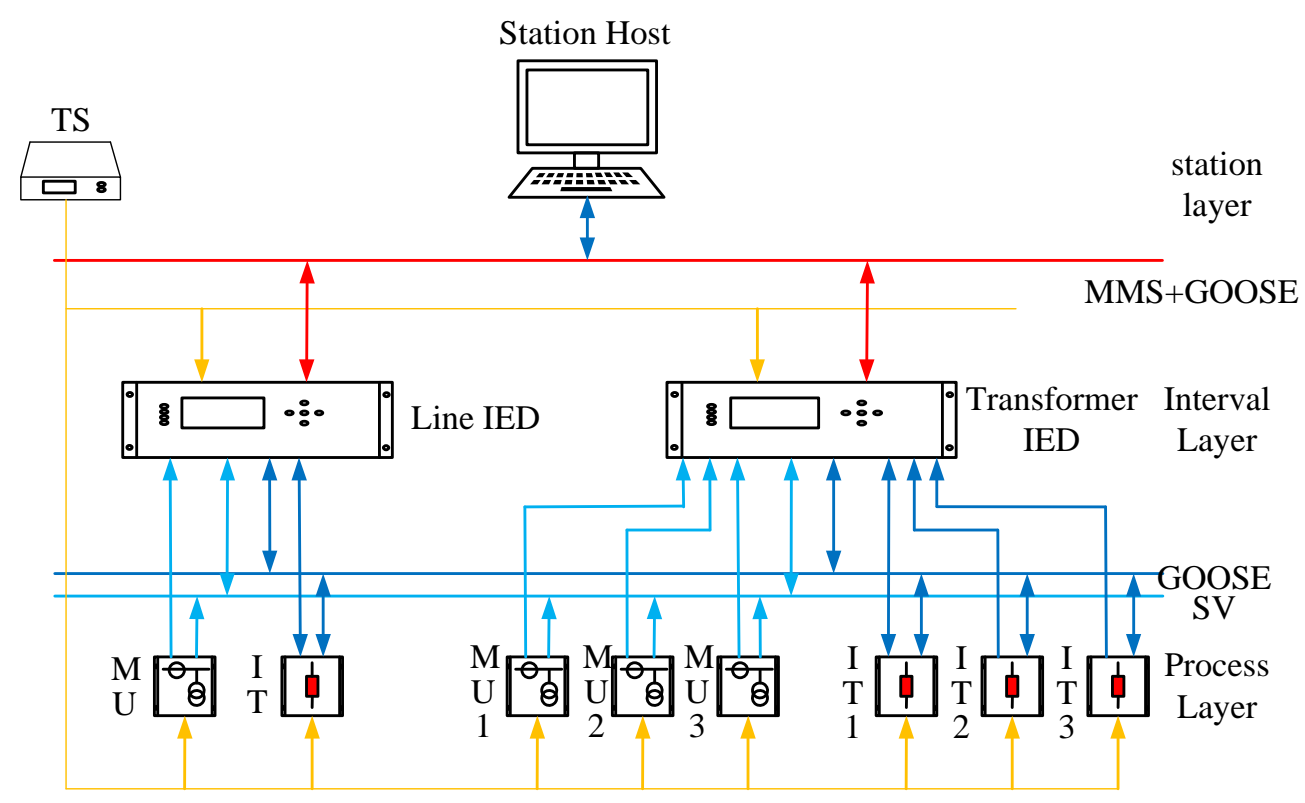

FIGURE I. TYPICAL ARCHITECTURE OF PROTECTION SYSTEM IN 110KV INTELLIGENT SUBSTATION

In the "direct collection" model, the relevant specification requires that the protection system can complete the protection function independently without relying on the external time, so the effect of time synchronous source is not considered in the reliability evaluation process. But for the "net collection" mode, the influence of time synchronous source should be counted due to the delay in the data transmission.

\section{ReLIABILITy EVALUATION}

\section{A. Reliability Block Diagrams(RBD) Method}

The reliability block diagram (RBD) is an important way to evaluate the overall reliability of a system. In this method, different parts or components in the system can be represented by boxes, and the effective or invalid logic of the system can be displayed through the interconnections between the boxes. The minimal path sets method is used to calculate the reliability of the system.

If the system consists of several components or subsystems and failure of any one of the components or subsystems will cause the system to fail, this system is called a tandem system and its reliability is calculated as:

$$
R_{s}=\prod_{k=1}^{n} R_{k}
$$

In (1), $R_{s}$ is the reliability of the entire system, $n$ is the number of components or subsystems in the system and $R_{k}$ is the reliability of component or subsystem $k$.

If the failure of all components in the system constitutes a failure of the system, this system is called a parallel system and its reliability calculation formula is:

$$
R_{s}=1-\prod_{k=1}^{n}\left(1-R_{k}\right)
$$

\section{B. Reliability Parameters of Protection Elements}

At present, it is generally believed that the failure of components is exponentially distributed in the study of relay protection reliability. Then the probability and failure probability of components at time $t$ can be obtained from the following formula:

$$
\begin{gathered}
A(t)=\frac{\mu}{\mu+\lambda}+\frac{\lambda}{\mu+\lambda} \mathrm{e}^{-(\mu+\lambda) t} \\
Q(t)=\frac{\lambda}{\mu+\lambda}\left[1-\mathrm{e}^{-(\mu+\lambda) t}\right]
\end{gathered}
$$

Where $\lambda$ and $\mu$ are respectively the failure rate and repair rate of component.

Under the stable maintenance and maintenance mechanism, for the repairable components, the $\lambda$ and $\mu$ can be seen as constant, which can be obtained from a large number of longterm statistics. In the process of evaluation, the value of $\lambda$ is taken referencing [2-5], which is shown in Table I, and for all components the value of $\mu$ is 365 times $/ y$. 
TABLE I. THE FAILURE RATE $\lambda$ OF DIFFERENT COMPONENT

\begin{tabular}{|c|c|}
\hline Component & Failure Rate $\lambda / \mathbf{y}$ \\
\hline MU(Merging Unit) & 0.0067 \\
\hline IED(Intelligent Electronic Device) & 0.0067 \\
\hline TS(Time Synchronisation Source) & 0.0067 \\
\hline SW(Switch) & 0.02 \\
\hline IT(Intelligent Terminal) & 0.0067 \\
\hline OF(Optical Fiber) & 0.001 \\
\hline EM(Ethernet Media) & 0.0067 \\
\hline
\end{tabular}

The system failure states caused by the failure of different types of components are also different. For information transmission elements such as OF and SW, when they themselves fail, they will only result in missing data and will not generate erroneous data, so the system may have a risk of "rejection" but there will be no risk of "misoperation". However, the components involved in data generation, data analysis and command execution process, such as MU, IED, EU, etc., in the event of a failure, may cause a "misoperation" or "rejection" of protection, therefore, the failure modes of such components are divided into the two states of "rejection" and "misoperation", and they are respectively considered to account for half of the total failure probability of the component, as is shown in Table II.

\section{TABLE II. THE WORKING PROBABILITY OF DIFFERENT} COMPONENT

\begin{tabular}{|c|c|c|c|}
\hline Component & $\begin{array}{c}\text { Working } \\
\text { Probability }\end{array}$ & $\begin{array}{c}\text { Rejection } \\
\text { Probability }\end{array}$ & $\begin{array}{c}\text { Misoperation } \\
\text { Probability }\end{array}$ \\
\hline MU & 0.99998164 & 0.00000918 & 0.00000918 \\
\hline IED & 0.99998164 & 0.00000918 & 0.00000918 \\
\hline TS & 0.99998164 & 0.00000918 & 0.00000918 \\
\hline SW & 0.99994521 & 0.00005479 & $/$ \\
\hline EU & 0.99998164 & 0.00000918 & 0.00000918 \\
\hline OF & 0.99999726 & 0.00000274 & $/$ \\
\hline EM & 0.99998164 & 0.00001836 & $/$ \\
\hline
\end{tabular}

C. Reliability Evaluation Method of The Relay Protection System in Smart Substation Considering Virtual Branch

At present, the State Grid Corporation stipulates that the protection of smart substations should adopt the "direct collection and direct tripping" approach. Therefore, the analysis of the reliability of the relay protection system in this paper is conducted in this way, but this method is also applicable to other operating modes.

If the impact of redundant information on improving the reliability of the protection system is not considered, reliability block diagrams of different protection types as shown in Figure II can be obtained. However, one of the main advantages of smart substations compared to traditional substations is that they can effectively use a large amount of redundant information in the stations to identify faulty components, thereby improving the reliability of protection. If the impact of information exchange between different components is ignored, the actual reliability of the protection system is underestimated. Therefore, a reliability evaluation method of relay protection system based on virtual branch in smart substation is presented, and the characteristics of intelligent substation using redundant information to identify faulty components are represented in the form of virtual branch.

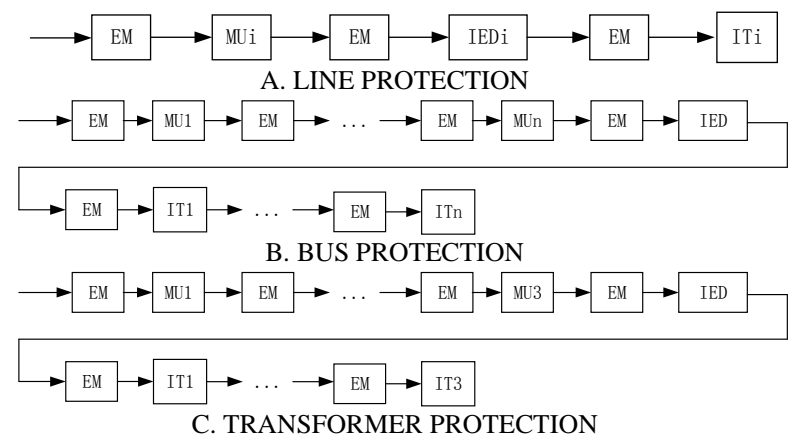

FIGURE II. RELIABILITY BLOCK DIAGRAMS OF DIFFERENT PROTECTION TYPES

Taking the line protection in Figure III as an example, if the merging unit on line 1 fails to work, the voltage at that point can be directly transmitted by the merging unit on the adjacent line to the protection device via the SMV network, and the line current can be obtained from the currents measured by other adjacent lines based on Kirchoff's current law (KCL):

$$
I_{i}=-\sum_{\substack{k=1 \\ k \neq i}}^{n} I_{k}
$$

Where $I_{i}$ and $I_{k}$ are respectively the currents flowing through line $L_{i}$ and $L_{k}$.

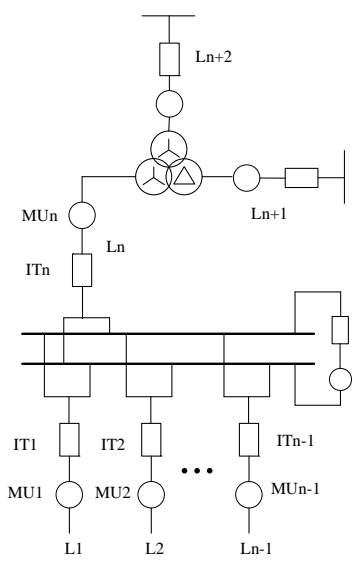

FIGURE III. PROTECTION ARCHITECTURE

That is, $\mathrm{MU}_{i}$ of line $L_{i}$ can be replaced by MUs of other adjacent lines. So, in the reliability block diagram, a virtual branch is connected in parallel on the original path, as shown in Figure IV, it's physical meaning is: The merging unit $\mathrm{MU}_{i}$ on the line $L_{i}$ receives the current and voltage information of the line normally and transfers it to the line protection device IED . $_{i}$ After the analysis and judgment by $\mathrm{IED}_{i}$, the command of whether to trip is sent to the intelligent terminal IT to complete the corresponding operation of the circuit breaker; and when 
$\mathrm{MU}_{i}$ refuses to move due to the failure, the MUs on all adjacent lines each transmit the electrical quantity information with the clock signal to the SV network through the switch. After receiving the above data from the SV network, the electrical quantity on the line $L_{i}$ can be obtained to complete the subsequent function.

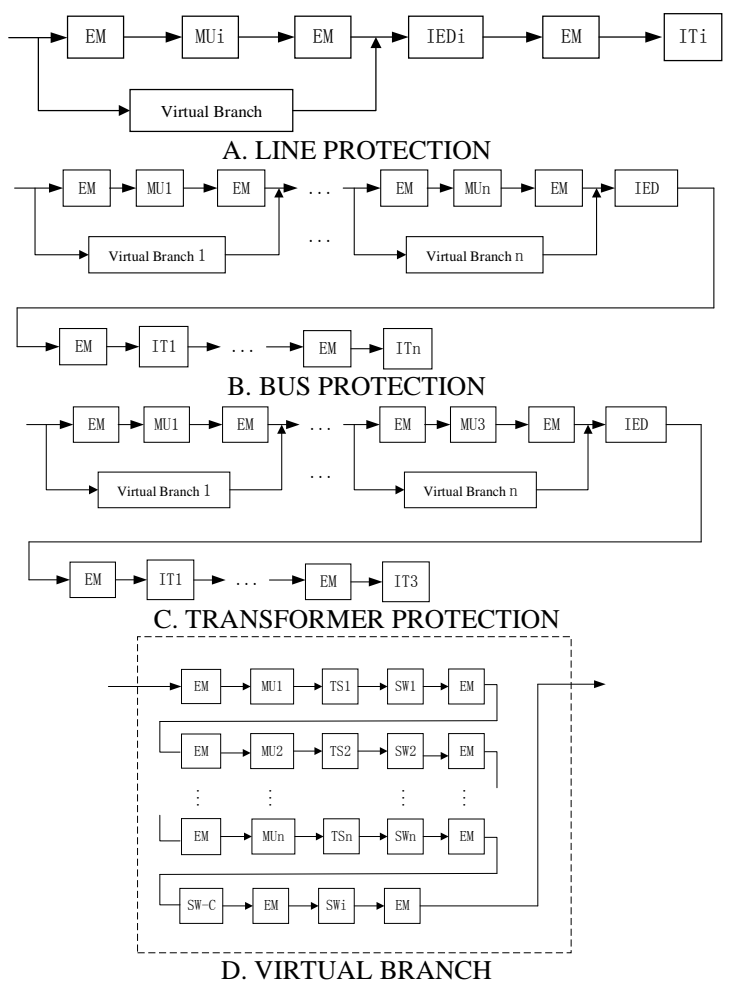

FIGURE IV. RELIABILITY BLOCK DIAGRAM OF DIFFERENT TYPES OF PROTECTION WITH VIRTUAL BRANCH

For the bus protection, since the main protection is mostly pilot protection, which needs to collect and analyze the current information of all relevant branches. Therefore, when the merging unit of the outgoing line L1 refuses to act, the virtual branch cannot be formed by the above method. However, when the merging unit on the incoming line $L_{n}$ refuses to move, a virtual branch can still be formed by the equipment on its adjacent line $L_{n+1}$ and $L_{n+2}$.

Transformer protection is similar to bus protection. Virtual currents cannot be formed between different voltage side currents using KCL, but each side can still use devices on adjacent lines to form virtual branches.

It should be noted that the above reliability analysis is based on the assumption that the component "rejection". When the component in the protection system "misoperation", the protection device will receive wrong information from the original line containing "misoperation" component and correct information from the virtual branch at the same time. According to the existing protection principle, the protection device will still trip. Therefore, the virtual tributary cannot prevent the protection from "misoperation". Under the "misoperation" fault, the reliability block diagram of the protection system will be degraded to a state without a virtual tributary.

\section{STUDY CASE}

Take the typical three-voltage-level smart substation shown in Figure $\mathrm{V}$ as an example, in which the voltage levels are $220 \mathrm{KV}, 110 \mathrm{KV}$, and $35 \mathrm{KV}$, respectively. The transformer substation adopts the electronic transformer and merging unit to achieve the collection of electric quantity; uses the conventional circuit breaker and intelligent terminal to realize the equipment intelligence; the SV and GOOSE networks are configured separately, and the data is transmitted over optical fibers.

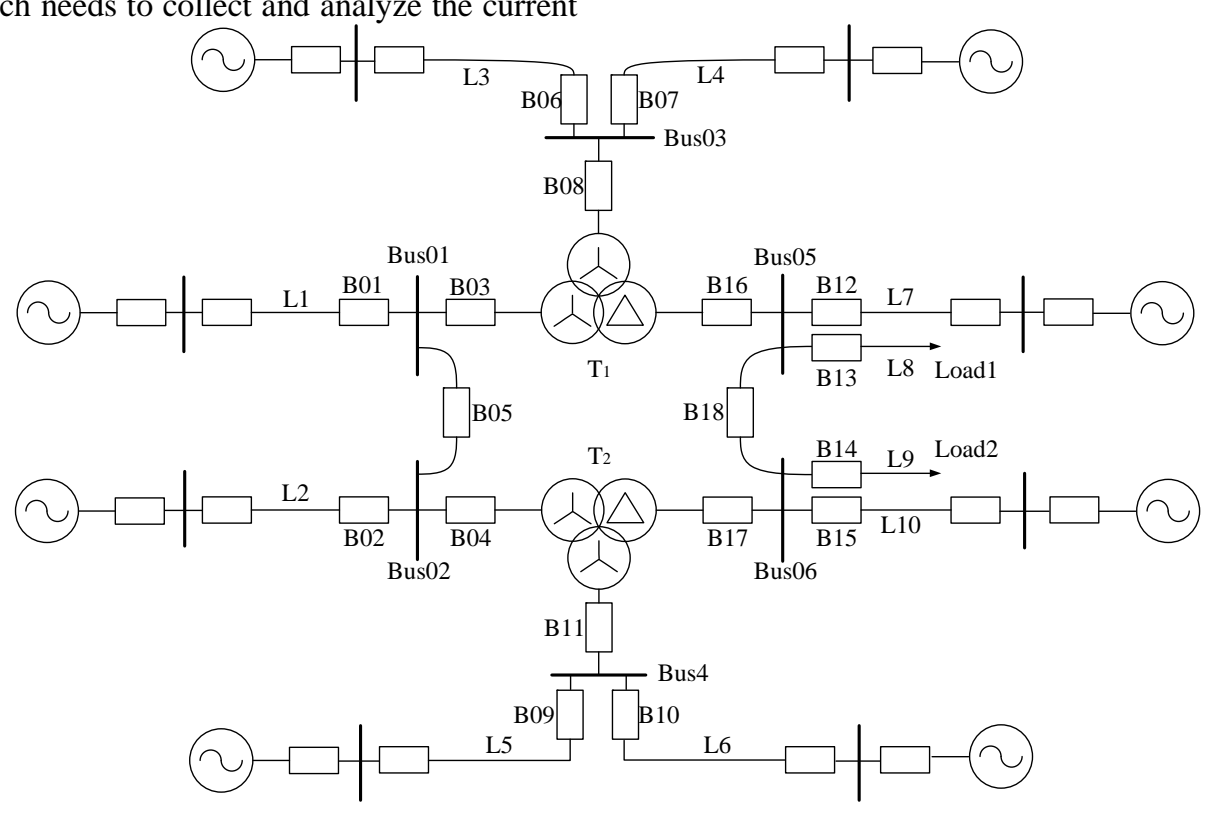

FIGURE V. THE TYPICAL STRUCTURE OF A THREE-VOLTAGE-LEVEL SMART SUBSTATION 
The reliability and unreliability of each type of relay protection systems obtained according to the method in this paper and the original method without virtual branch are shown in Table III. The two algorithms will obtain the same unreliability when the virtual branch fails under the "misoperation" fault, so this situation is not split.

For ease of observation, the reliability of different types of protection system obtained by the two algorithms is represented by a curve, as shown in Figure VI. It can be seen that the reliability of the line protection, bus protection and transformer protection obtained by this method is improved to a different extent than the original method without virtual branches.

Figure VII is a failure probability curve of different types of relay protection systems caused by "rejection". After calculation, considering the virtual branch, the failure probability of line protection, bus protection and transformer protection caused by the component "rejection" is reduced by $40.98 \%, 11.00 \%$ and $46.12 \%$ respectively compared with the original method.

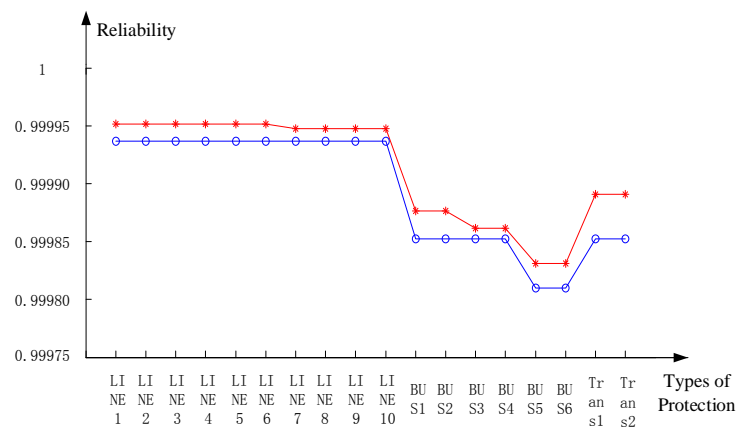

FIGURE VI. THE RELIABILITY OF DIFFERENT TYPES OF PROTECTION SYSTEM

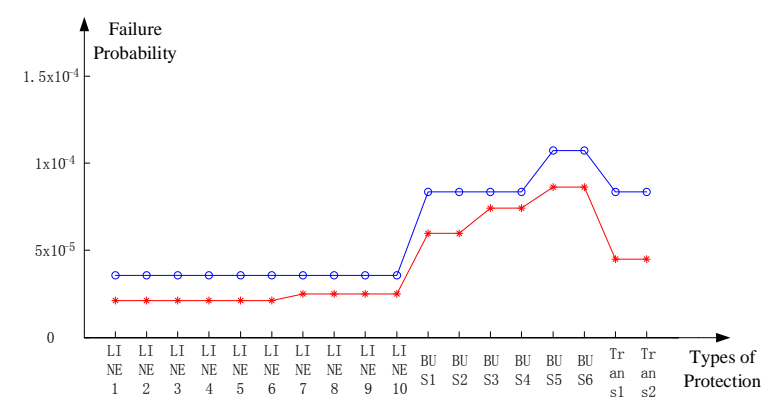

FIGURE VII. FAILURE PROBABILITY OF DIFFERENT TYPES OF RELAY PROTECTION SYSTEMS CAUSED BY “REJECTION"

In addition, comparing the data in Table III, it can be seen that the reliability of the different line protection systems calculated by the original method is the same, but by the new method they are different. For example, the reliability of line L1 and line L7 is 0.99995136 and 0.99994736 respectively. The reason is that the original method only considers the reliability of the line elements and has nothing to do with the relationship between adjacent lines. But in the new method, the establishment of virtual branches is related to the topology of adjacent lines, so the protection reliability of different lines is not the same.
TABLE III. THE RELIABILITY AND UNRELIABILITY OF EACH TYPE OF RELAY PROTECTION SYSTEMS

\begin{tabular}{|c|c|c|c|c|c|}
\hline \multirow{3}{*}{ Name } & \multicolumn{2}{|c|}{ Reliability } & \multicolumn{3}{|c|}{ Unreliability } \\
\hline & \multirow{2}{*}{$\begin{array}{l}\text { Original } \\
\text { Method }\end{array}$} & \multirow{2}{*}{$\begin{array}{c}\text { New } \\
\text { Method }\end{array}$} & \multicolumn{2}{|c|}{ "rejection fault" } & \multirow{2}{*}{$\begin{array}{l}\text { "miso } \\
\text { peration } \\
\text { " fault }\end{array}$} \\
\hline & & & $\begin{array}{l}\text { Original } \\
\text { Method }\end{array}$ & $\begin{array}{c}\text { New } \\
\text { Method }\end{array}$ & \\
\hline \multirow{2}{*}{ Line 1} & 0.999936 & 0.999951 & 3.5752E- & 2.1099E- & 2.7533 \\
\hline & 71 & 36 & 05 & 05 & E-05 \\
\hline \multirow{2}{*}{ Line 2} & 0.999936 & 0.999951 & 3.5752E- & 2.1099E- & 2.7533 \\
\hline & 71 & 36 & 05 & 05 & E-05 \\
\hline \multirow{2}{*}{ Line 3} & 0.999936 & 0.9999951 & 3.5752E- & 2.1099E- & 2.7533 \\
\hline & 71 & 36 & 05 & 05 & E-05 \\
\hline \multirow{2}{*}{ Line 4} & 0.999936 & 0.9999951 & 3.5752E- & 2.1099E- & 2.7533 \\
\hline & 71 & 36 & 05 & 05 & E-05 \\
\hline \multirow{2}{*}{ Line 5} & 0.999936 & 0.999951 & 3.5752E- & 2.1099E- & 2.7533 \\
\hline & 71 & 36 & 05 & 05 & E-05 \\
\hline \multirow{2}{*}{ Line 6} & 0.999936 & 0.999951 & 3.5752E- & 2.1099E- & 2.7533 \\
\hline & 71 & 36 & 05 & 05 & E-05 \\
\hline \multirow{2}{*}{ Line 7} & 0.999936 & 0.999947 & 3.5752E- & 2.5100E- & 2.7533 \\
\hline & 71 & 36 & 05 & 05 & E-05 \\
\hline \multirow{2}{*}{ Line 8} & 0.999936 & 0.999947 & 3.5752E- & 2.5100E- & 2.7533 \\
\hline & 71 & 36 & 05 & 05 & E-05 \\
\hline \multirow{2}{*}{ Line 9} & 0.999936 & 0.999947 & 3.5752E- & $2.5100 \mathrm{E}-$ & 2.7533 \\
\hline & 71 & 36 & 05 & 05 & E-05 \\
\hline \multirow{2}{*}{$\begin{array}{c}\text { Line } \\
10 \\
\end{array}$} & 0.999936 & 0.999947 & 3.5752E- & 2.5100E- & 2.7533 \\
\hline & 71 & 36 & 05 & 05 & E-05 \\
\hline \multirow{2}{*}{ Bus 1} & 0.999852 & 0.999876 & 8.3420E- & 5.9595E- & 6.4244 \\
\hline & 33 & 16 & 05 & 05 & E-05 \\
\hline \multirow{2}{*}{ Bus 2} & 0.999852 & 0.999876 & 8.3420E- & 5.9595E- & 6.4244 \\
\hline & 33 & 16 & 05 & 05 & E-05 \\
\hline \multirow{2}{*}{ Bus 3} & 0.999852 & 0.999861 & 8.3420E- & 7.4247E- & 6.4244 \\
\hline & 33 & 50 & 05 & 05 & E-05 \\
\hline \multirow{2}{*}{ Bus 4} & 0.999852 & 0.999861 & 8.3420E- & 7.4247E- & 6.4244 \\
\hline & 33 & 50 & 05 & 05 & $\mathrm{E}-05$ \\
\hline \multirow{2}{*}{ Bus 5} & 0.999810 & 0.999831 & $1.0725 \mathrm{E}-$ & 8.6169E- & 8.2598 \\
\hline & 14 & 23 & 04 & 05 & E-05 \\
\hline \multirow{2}{*}{ Bus 6} & 0.999810 & 0.999831 & $1.0725 \mathrm{E}-$ & 8.6169E- & 8.2598 \\
\hline & 14 & 23 & 04 & 05 & E-05 \\
\hline Transf & 0.999852 & 0.999890 & 8.3420E- & 4.4943E- & 6.4244 \\
\hline $\begin{array}{c}\text { Ormer } \\
1\end{array}$ & 33 & 81 & 05 & 05 & E-05 \\
\hline $\begin{array}{l}\text { Transf } \\
\text { ormer }\end{array}$ & 0.999852 & 0.999890 & 8.3420E- & 4.4943E- & 6.4244 \\
\hline $\begin{array}{l}\text { ormer } \\
2\end{array}$ & 33 & 81 & 05 & 05 & E-05 \\
\hline
\end{tabular}

\section{CONCLUSION}

A method to evaluate the reliability of relay protection system in smart substations based on virtual branch is proposed in this paper. This method comprehensively considers the impact of information redundancy and data exchange of smart substation on the reliability of different types of protections, so it can effectively avoid the underestimation of the protection reliability. The results of the case show that considering the exchange of information, the reliability of the line protection, bus protection and transformer protection in the station has been improved to a different degree than when it was not considered. In particular, the failure probability of the protection system caused by component "rejection" has been 
significantly reduced. The validity of the method can provide reference for the design and planning of the protection system of the smart substation.

\section{ACKNOWLEDGMENT}

This work was supported by Scientific and Technical project of State Grid Zhejiang Electric Power Corporation.

Project No. 5211jx150107

\section{REFERENCES}

[1] Huang Yizhuang, "Smart substation is the further objective of SAS," Power System Protection and Control, 2013, 41(2): 88-92.

[2] Fan Chen, Ni Yimin, Shen Hong, et al. "Comparative analysis on development of smart substations in China and Europe," Automation of Electric Power System ,2015, 39(16) : 1-7.

[3] Zhang Peichao, Gao Xiang. "Analysis of reliability and component importance for all-digital protective systems," Proceedings of the CSEE, 2008, 28(1): 77-82.

[4] Wang Tongwen, Xie Min, Sun Yueqin, et al. "Analysis of reliability for relay protection systems in smart substation," Power System Protection and Control, 2015, 43(6): 58-66.

[5] Wang Chao, Wang Huifang, Zhang Chi, et al. "Study of reliability modeling for relay protection system in digital substations," Power System Protection and Control, 2013, 41(3): 8-13.

[6] Du Shuangyu, Wang Xianpei, Xie Guangbin, et al. "Reliability evaluation of substation automation system based on IEC61850," Power System Protection and Control, 2012, 40(5): 32-36, 41.

[7] LIU Yang, Ma Jin, Zhang Ji, et al. Reliability evaluation of a new generation smart substation considering relay protection system[J]. Power System Protection and Control, 2013, 41(18): 142-148.

[8] Zhang Zhirui, Xiao Fan, Jiao Shaolin, et al. "Reliability evaluation of protective relay system based on process layer network," Power System Protection and Control, 2013, 41(18): 142-148.

[9] Han Xiaotao, Yin Xianggen, Zhang Zhe. Application of fahlt tree analysis method in reliability analysis of substation communication system [J]. Power System Technology, 2004, 28(1):56-59.

[10] Sun Fushou, Wang Xionghai. "A new method for reliability analysis of protection in power systems," Automation of Electric Power Systems, 2006, 30(16):32-35.

[11] Xu Tianqi, Li Yan, Yin Xianggen, et al. "Reliability assessment of digital substation automation system," Automation of Electric Power System, 2011, 35(19):12-17.

[12] Huo Chao, Zhang Peichao. "An analysis of component importance considering the cost for all-digital protection systems," Automation of Electric Power Systems, 2007, 31(13): 57-62.

[13] Zhang Yueli, Chen Xingqiong, Wang Chengmin, et al. "Reliability assessment of intelligent substation secondary system," Power System and Clean Energy, 2012, 28(11): 7-12.

[14] Li Jungang, Liu Xing, Zhang Aimin, et al. "Research on redundant technology of IEEE1588 clock synchronization system in smart substation,” Power System Protection and Control, 2015, 43(20): 97-101. 